\title{
El Cambio en Psicoterapia Psicodramática: De la Acción a la Reparación
}

\section{The change in Psychodramatic Psychotherapy: From Action to Psychological Restoration}

\author{
Teodoro Herranz Castillo \\ Asociación para el Estudio de la Psicoterapia y el Psicodrama, España
}

\begin{abstract}
Resumen. En el presente trabajo abordamos nuestra comprensión del cambio en psicoterapia psicodramática. Para ello buscaremos en la teoría los conceptos sobre los que se construye la intervención terapéutica: los conceptos de rol, contra rol, dramatización, actuación y proceso. Nos detendremos en la comprensión del cambio a la luz de la teoría y de la experiencia clínica, ¿qué creemos desde nuestro pensamiento que genera el cambio? y ¿qué nos dicen las personas que han participado en sesiones de psicodrama que les ha servido para mejorar sus vidas?
\end{abstract}

Palabras clave: psicoterapia psicodramática, cambio, resistencias, proceso terapéutico, cambio terapéutico.

Summary. In the present study the Psychodramatic concept of change was investigated. We analyzed the essential concepts of Psychodramatic theory, rol, theory, psychodrama enactment, resistance, processes, and therapeutic change.

We reflected on the concept of change in light of Psychodramatic theory and clinical experience. The most important clinical variables for the change are identified. A comparison was made to what patients believed were the most important factors to them in a Psychodramatic therapy.

Keywords: psychodrama psychotherapy, change, resistance, therapeutic change, therapeutic process.

\section{La teoría del psicodrama}

El gran peligro para los terapeutas es que sus teorías más queridas tienen un alto riesgo de volverse profecías autorrealizables. (Monteiro, 2000).

El psicodrama ha estado siempre sometido a interrogaciones en la formulación de su teoría, lo que, en algún caso, ha llevado a considerarlo una técnica sin teoría.

Perazzo (2004) en un intento de organizar los diferentes abordajes actuales del psicodrama nos dice:

"Sus múltiples aplicaciones, a través de la psicoterapia de grupo, de la psicoterapia individual

La correspondencia sobre este artículo puede dirigirse al E-mail: teo@vienacapellanes.com 
bipersonal (más reciente y cada vez más difundida hoy en algunos países como Brasil y Argentina, por ejemplo), de su actuación educacional y comunitaria por medio de su métodos de Role-Playing, Sociodrama y Axiodrama, de su vertiente de producción cultural (arte dramática creativa) por medio del teatro espontáneo, crean un enorme desafío para ubicarlos de forma coherente y abarcativa, en el plano teórico, si es que es posible, todos estos desdoblamientos de la práctica psicodramática, en nuestro esfuerzo y necesidad de asirlos didácticamente en algún marco clasificatorio que nos alivie de la angustia del espíritu y del alma y que nos reconozca sin titubeos como Psicodramatistas”. (Perazzo, 1994, p. 21).

Pero si buscamos lo común, lo que nos define como psicodramatistas me quedo con una conclusión del propio Perazzo. Se trata, por tanto de un proceso de co-creación que tiene por fundamento inicial la espontaneidad-creatividad de cada individuo a transformar, conjuntamente, un modo de relación mediado por roles en algo único y nuevo y al mismo tiempo de uno y de todos.

\section{Cómo se realiza una sesión de psicodrama}

Lo común, lo compartido podemos verlo en el modo de actuar, con diferencias ligadas a los distintos modos de pensarlo o a las cualidades de quien lo realiza. Pero lo común, lo no cuestionado es el procedimiento en el sentido más puramente moreniano.

Hay tres fases en una dramatización. De una manera descriptiva vamos a considerar que la sesión de psicodrama debe seguir un proceso, la idea de continuidad, de secuencia, es fundamental para diferenciar el psicodrama del uso de las técnicas psicodramáticas.

La primera fase es el Caldeamiento, es una fase de preparación del grupo con más precisión, es la fase inicial donde el grupo habla, realiza ejercicios, etc. Se le denomina caldeamiento inespecífico donde el grupo está generando una disposición emocional que le permita abordar un conflicto. La función del director, del terapeuta, es de catalizador o facilitador.

El final de esta fase vendrá marcado por la aparición de una escena, grupal o individual en la que una persona plantea algo de sí misma que quiere conocer, resolver, etc. O bien se produce alguna interacción o dinámica entre los miembros del grupo como tal, o entre algunos de los participantes. En este momento el terapeuta pasará a ayudar en la construcción de la escena, su localización temporal, espacial, etc. Esta actividad se denomina caldeamiento específico.

La segunda fase es la Dramatización, es el paso a la representación, es el momento en que el paciente va a plantear sus conflictos, sus dificultades, y lo va a hacer actuándolo en vez de narrándolo. Los personajes internos del paciente van a aparecer junto a él y fuera de él.

"Localizada la escena a dramatizar, el protagonista no relata lo que ocurre sino que va cambiando roles con los yoes auxiliares y así va armando una acción que responde a la externalización del mundo interno del protagonista" (Bustos, 1985, p.24).

En esta fase el terapeuta puede utilizar las técnicas psicodramáticas con el fin de facilitar la dramatización.

La tercera fase de la sesión psicodramática es el Comentario, el Compartir. Los miembros del grupo hablan desde ellos, comparten su vivencia, su experiencia con relación al protagonista, no se valora, no se juzga, está absolutamente contraindicado. Esta fase es fundamental, el grupo tiene que cohesionarse desde lo vivido, y tiene que elaborar junto con el protagonista, la experiencia que están viviendo.

Este momento es importante para el grupo y el protagonista. Es necesario que el terapeuta favorezca la expresión de todos los miembros del grupo, es importante que la elaboración permita el autorreconocimiento en los miembros del grupo, que pasarán a convertirse en posibles escenas en próximas sesiones. 


\section{Proceso de intervención psicodramático}

\section{El encuentro en psicodrama}

Antes de introducirnos en compartir qué es un proceso terapéutico, es imprescindible explicar EL CONCEPTO DE ENCUENTRO, tan querido para la psicoterapia en general, y especialmente para el psicodrama. La revisión de este concepto lo haremos siguiendo las pautas marcadas por Dalmiro Bustos (1985) en una reflexión desde su propia vivencia en su aplicación a la práctica terapéutica.

En primer lugar, nos encontramos con que el concepto de Encuentro no es privativo de ninguna escuela de psicoterapia, pero sí es necesario precisar qué entendemos en psicodrama por Encuentro.

- "El concepto de encuentro surge en Moreno mucho antes de aparecer el Psicodrama. (...) La noción de Encuentro está presente ya en sus primeras obras como en su anónimamente presentado primer libro "Las palabras del padre". (Bustos, 1985, p.26).

A continuación Dalmiro (1985) nos ofrece un apunte de definición de J. L Moreno:

- "Encuentro significa más que una vaga relación interpersonal -ZWISCHEN MENSSCHLICHE BEZIEHUNG- Significa que dos o más personas se encuentran, pero no solamente para enfrentarlas, sino para vivir y experimentarse mutuamente. En un encuentro las dos personas están allí, con todas sus fuerzas y sus debilidades, dos actores humanos bullendo de espontaneidad, sólo en parte conscientes de sus fines comunes. (Moreno, 1961, p.336).

La interpretación de esta definición de Encuentro en su aplicación a la psicoterapia devendrá en lo que consideramos distintos procesos posibles de psicoterapia. La primera pregunta a hacerse es qué significa en una situación terapéutica "que dos o más personas se encuentran (...) para vivir y experimentarse mutuamente".

Podemos optar por una posición de Encuentro entendiéndola como una posición terapéutica, donde tanto el paciente como el terapeuta se permiten compartir "partes de sí mismo, confidencias, recuerdos", con la idea de que no deben existir zonas oscuras entre dos seres humanos. Dalmiro, en su formación en Beacon con Zerka Moreno, nos dice que le llamaba poderosamente la atención esta actitud en Zerka:

- "Ella era igual a sí misma dentro y fuera de la relación terapéutica. Compartía aspectos de su vida durante el sharing, se enojaba, reía, era un ser humano con todas las limitaciones y falibilidades. Cuando dirigía se la sentía allí, entera”. (Bustos, 1985, p.27).

Esta actitud terapéutica, hay que situarla dentro de su contexto, Dalmiro nos dice que en Beacon no se trabajaba con una idea de proceso terapéutico, sino que eran encuentros de pocos días de duración, donde eran flexibles los roles, se permutaban los papeles de director, yoes auxiliares, etc.

Pero hay una dificultad en este modo de trabajar, ¿hasta dónde se puede pedir a un terapeuta que comparta aspectos de su privacidad o de su intimidad, sin preguntarse por la oportunidad, la utilidad y quizás la honestidad de los mismos?

Pero Dalmiro va más allá en su análisis, cuando se plantea que los momentos de compartir del terapeuta, no son ajenos al proceso terapéutico, no se recogen igual los comentarios, o los recuerdos del terapeuta, en función de cómo sea la relación que en ese momento existe entre ambos.

- "Si la experiencia compartida por el Director caía en un momento télico de la relación, la sensación de enriquecimiento mutuo era clara. Pero ¿cuántas veces sentí que esto ocurría? Si el momento era transferencial, ¿Cuál era la resignificación del mensaje en el mundo interior del o de los pacientes?” (Bustos, 1985, p.28).

Esta dificultad de compartir sin considerar el momento terapéutico y la solidez de la relación terapéutica, nos ha llevado a todos los que empezamos, quizás con una mala interpretación del concepto de espontaneidad a fracasos terapéuticos.

- "Fragmento extraído de una sesión con una paciente: P: Yo quiero ser una piedra porque las piedras no sufren. T: Yo también lo intenté pero no pude conseguirlo. P: Pero he intentado matarme. T: No me dices nada que no conozca. P: Vaya desilusión, yo que te tenía por un señor, que iba con maletín, con una carrera... y ahora me dices esto, vaya desengaño" (Herranz, 1990, p. 69). 
Si el encuentro no es ajeno al proceso terapéutico, si el encuentro supone reevaluar la eficacia de este compartir desde la intimidad, ¿cómo podemos implementar en nuestro modo de actuación, este principio que guía nuestro trabajo?

Recojo una vez más la posición que Dalmiro (1985, p.34) sostiene al respecto:

- "La relación terapéutica es por definición desigual (...). La asimetría está dada y es bueno que así sea, de lo contrario no se puede operar terapéuticamente. ¿Hay Encuentros asimétricos?... Se debe recordar lo que Freud nos decía, "finalmente todo conflicto debe librarse en la esfera de la transferencia". (Villamarzo, 1991, p.36)

Llegados a este punto, creo que lo que nos está planteado Dalmiro es una de las confusiones teóricas que nos han llevado a opciones clínicas un tanto dudosas y que en este momento podríamos formular a modo de pregunta: ¿El encuentro es el punto de inicio del tratamiento, o es el punto de llegada? Sin entrar en la actitud de partida con la que el terapeuta recoge al paciente, desde luego si no parte de una postura de acogida no creo que pueda tener cabida ningún proyecto realmente terapéutico.

Partiendo de la experiencia que la clínica nos ha enseñado, el siguiente paso es establecer las condiciones para que ese "Encuentro" enriquecedor y terapéutico pueda producirse.

- "Si en la relación terapéutica hay adecuación a las reglas, si hay participación emocional y entrega, hay Encuentro (...) A las reglas claras de una posición distante hay que oponerse con reglas claras de la posición de Encuentro, ya que de lo contrario quedan sentadas las bases para la anarquía” (Bustos, 1985 p.31).

A modo de conclusión y haciendo mía la posición que sostiene Dalmiro, podemos finalizar con el principio desde el que opera un psicoterapeuta psicodramático:

- "Coincido con Buber en su formula básica de Yo-Tu, como ideal no objetivante. Con Perls en su obstinado presentismo y con Rogers en su insistencia sobre la autenticidad como única posibilidad de proporcionar la continencia necesaria para el crecimiento. Si esta propuesta está clara en el terapeuta, éste sabrá recrearla en sus relaciones individuales y también en los grupos terapéuticos. (...) Pero la posición existencial no depende de la técnica que se utilice" (Bustos, 1985, p.33).

\section{Concepción de proceso terapéutico}

1. ¿Acto frente a proceso?

En primer lugar tenemos que diferenciar la idea de proceso terapéutico, de una concepción de psicoterapia cada vez más utilizada por algunas corrientes de psicoterapia breve como acto terapéutico.

Un proceso terapéutico supone dotar a los actos terapéuticos de un orden temporal, respetando unas reglas que orientan qué tipos de intervenciones "actos terapéuticos" son aconsejables y cuáles o no lo son o pueden estar contraindicados.

Esto no significa que no exista cabida para la espontaneidad-creatividad, ni que el proceso sea una secuencia lineal y estática, este proceso es en última instancia, la creación de una relación humana.

"El concepto proceso, colocado en la relación paciente-terapeuta, significa que vamos a considerar la relación terapéutica como la consecuencia de una mutua influencia de conocimientos, conductas y sentimientos que se van a compartir a lo largo del tiempo" (Herranz 1999c, p.105).

Y, por tanto, cada tratamiento será la implementación de un procedimiento que tendrá que adaptarse a las particularidades de los que intervienen en el mismo, pero preservando una organización común.

\section{Las resistencias}

Todas las psicoterapias se encuentran con la dificultad para cambiar, por lo que la resistencia ha pasado a considerarse un componente de la psicoterapia, como los síntomas o los recursos del paciente. 
Una vez que reconocemos que existe un "fenómeno" que vamos a encontrar en nuestro trabajo con los pacientes, es necesario saber cómo lo entendemos:

El psicodrama Moreniano acepta y reconoce el fenómeno de la resistencia, una aproximación a su definición podría ser la siguiente:

- "Un reto básico en la psicoterapia o psicodrama es el de ayudar al protagonista a encontrar la forma de examinar aquellos sentimientos internos que están amenazando su sentimiento de dominio o autoestima" (Blatner, 1973, p.60).

Así como la importancia que tiene el tratamiento de las resistencias en psicodrama:

- "Tratar con las resistencias del protagonista es el centro de la psicoterapia o psicodrama" (Blatner, 1973, p.61).

El psicodrama comparte con el psicoanálisis la existencia del mundo inconsciente, incluso en ocasiones ha hecho referencia al "Inconsciente Colectivo".

\section{3. ¿Cómo se abordan las resistencias en psicodrama?}

- "El Dr. Moreno lo expresa de la siguiente manera: nosotros no destruimos las paredes del protagonista, más bien probamos algunas de las perillas en las muchas puertas y vemos cual se abre" (Blatner, 1973, p.60).

Antes de abordar una dificultad hay que reconocerla:

- "El primer paso al mostrar las resistencias del protagonista es la clara identificación y expresión de la manera en que evita la situación" (Blatner, 1973, p.60).

Desde el modo de pensar la resistencia que aquí hemos compartido, entendemos que la resistencia cumple una función protectora de un peligro mayor para el paciente que las limitaciones que le supone. Por tanto, lo que podemos realizar son diferentes técnicas que nos lleven a identificar qué teme el paciente, sin importar que este temor sea una apariencia de otros menos conocidos para él.

Se puede exagerar la defensa, intensificarla...

- "La resistencia expresada en la tendencia a explicar, puede ser presentada abiertamente por el director al pedir al protagonista que hable al grupo, que explique su posición durante un minuto" (Blatner, 1973, p.60).

Podemos acompañar las dificultades con diferentes estrategias verbales que le hagan al paciente ganar confianza en sí mismo: recurrimos a parafrasear lo que dice, lo redefinimos, etc.

- "No sé" puede ser expresado como "No quiero pensar en eso".

- “Por qué tengo que hacer esto?” puede reemplazarse por "No me gusta hacer eso".

Como se puede apreciar, se pretende que el paciente pueda sentirse en un "rol" que le aleje del sentimiento de impotencia e incapacidad.

Podemos aumentar el sentimiento de control sobre sus resistencias: no es lo mismo "no hacer", que "decidir no hacer"; no es lo mismo sentirse pasivo frente a lo que le pasa, que tener la impresión de que está eligiendo lo que le pasa.

- "El objeto de ir con las resistencias es que, por medio de la presentación expícita de las defensas del protagonista, es más consciente de que está eligiendo usar una defensa (...). Cuanto más pueda el protagonista, con la ayuda del director, decir "No", más pronto comenzará a sentirse libre para decir "sí”, cuando esté listo (Blatner, 1973, p.60).

Otro modo de ayudar con las resistencias a los pacientes consiste en manejar la distancia emocional con las situaciones representadas. Un principio en la intervención con psicodrama es ir de lo periférico a lo central, las resistencias pueden ser la combinación de dos factores que intervienen en la dramatización: el proceso de caldeamiento y la intensidad del temor del paciente. 
El caldeamiento es el estado de preparación del sujeto para la dramatización, sólo sabemos si es suficiente por su efecto en la dramatización; supone en alguna medida una "cierta alteración de la conciencia" (Blatner, 2002a, 2002b). Por eso si apreciamos que el sujeto es incapaz de continuar, se paraliza, usa el lenguaje como una estrategia para alejarse de la dramatización, podemos ayudarle a que sienta mayor control sobre sí mismo, alejándole del centro del conflicto.

- "Con un protagonista que se está convirtiendo en súper ansioso mientras trata con un problema, con frecuencia resulta apropiado permitirle alejarse del centro del conflicto para obtener cierta distancia” (Blatner, 1973, p.62)

Otra manera de mostrarse la resistencia es la incapacidad del sujeto para reconocer sus sentimientos, aísla el afecto de la dramatización y la representación le resulta conocida pero ajena. La dramatización tiene utilidad sólo si el sujeto es capaz de reconocer el sentimiento dentro de sí mismo. Para ello podemos recurrir a técnicas que faciliten el acceso al sentimiento sin recurrir a la expresión verbal. El psicodrama utiliza con frecuencia técnicas que se apoyan en lo gestual, lo postural, lo corporal como un modo de acceder al mundo de los sentimientos del paciente. Por ello podemos recurrir al uso del cuerpo para el reconocimiento del sentimiento.

- "Al tratar con la sensibilización de un protagonista a sus propios sentimientos, el director se enfoca en las comunicaciones no verbales e imágenes del protagonista. Estas dos avenidas al inconsciente desvían la forma más común de todas las resistencias: La intelectualización, vaguedad, explicación, racionalización, abstracción y circunstancialidad" (Blatner, 1973, p.61).

Uno de los posibles modos de abordar las resistencias desde la comunicación no verbal del paciente a través de su cuerpo, podría ser identificar su cuerpo con una multitud de personajes que reflejen partes antagónicas de sí mismo. La lucha está encarnada, es corporal, y recurrimos a la simbolización de lo corporal como vía de acceso al sentimiento omitido, excluido, temido....

- "La comunicación no verbal del protagonista se dramatiza tratando las partes del protagonista como si fueran seres activos en sí mismos, áreas de tensión en el cuerpo, dureza en la voz, fuerza en las manos, todo puede representarse como un encuentro entre diferentes partes del yo" (Blatner, 1973, p.61).

\section{4. ¿ Existen diferentes niveles de comprensión de la resistencia en psicodrama?}

Desde una concepción de proceso terapéutico, existen tres niveles a la hora de entender la aparición de una resistencia, ya sea en el trabajo grupal o individual.

La idea esencial que mantenemos es que la angustia inhibe al sujeto, y nos informa de la cercanía de los conflictos no resueltos. Ahora bien, cuando trabajamos con un paciente esta resistencia hay que reconocerla desde:

- El momento grupal.

- La naturaleza de la escena a dramatizar (la naturaleza del conflicto).

- La relación paciente-terapeuta-grupo y la relación paciente-personajes internos (objetos internos).

El momento grupal o fase del tratamiento individual determina las ansiedades que caracterizan la resistencia. En el inicio de un tratamiento las resistencias van ligadas al miedo a la exposición, al otro, que se traducen en el miedo a la crítica, a la descalificación..., son los fantasmas persecutorios que nos acompañan. Pero lo que nos interesa remarcar es que, en estos momentos iniciales del tratamiento, las ansiedades representan una preocupación predominantemente por lo externo, por el otro, en la medida que el otro está investido con todos nuestros temores y desde ahí envuelto en los mismos.

Si pasada la fase inicial del tratamiento, cuando ya se ha constituido el grupo, existe un sentimiento de pertenencia grupal, o en el caso de un tratamiento individual la relación paciente-terapeuta está suficientemente consolidada, (se ha establecido una sólida alianza terapéutica), interpretaremos las resistencias del paciente ligadas a sus conflictos internos. 
No obstante los elementos transferenciales pueden aparecer en cualquier fase del desarrollo grupal, y los pacientes pueden adoptar una posición defensiva frente al grupo, si bien desde mi experiencia lo que observo es que a medida que el grupo va evolucionando esos movimientos hacia lo transferencial y lo distorsionado en la relación con el otro van disminuyendo. La realidad es el otro presentacional y no las imágenes proyectadas en el otro.

- "Para que la distinción entre tele y transferencia sea posible, lo primero que debe ser tomado en cuenta por el terapeuta, es el carácter fugaz tanto del tele como el de su aspecto transferencial. No se trata de estados, sino de alternativas de un vínculo que comprenden un momento. Un vínculo que en un momento es télico, puede ser transferencial en el momento siguiente" (Bustos, 1985, p.33).

Ej. Después de que Luis nos hubiera relatado una situación que le generaba sufrimiento en su relación de pareja y haberla dramatizado, observamos su incomodidad, su preocupación por el grupo. Detenemos la dramatización para hablar sobre su preocupación, y nos apunta su miedo a qué puedan pensar los otros de él, y añade desde la negación, "aunque no me importa porque yo tengo que ir a lo mío, me tiene que dar igual lo que piensen los demás".

La naturaleza de la escena a dramatizar: Recordemos que las escenas a dramatizar suponen la externalización de nuestro mundo interno, imágenes habitualmente dolorosas para el sujeto: carenciales, opresivas, que van a poner en evidencia sus defensas, que le van a mostrar ante sí mismo y ante los demás. Por eso es fundamental seguir una regla de intervención que yo aprendí de Dalmiro Bustos, tenemos que trabajar con la suficiente distancia emocional para que el sujeto pueda elaborar las emociones que se están movilizando, si la angustia desborda, la escena se detiene o puede tener una naturaleza más actuante que elaborativa.

Para Dalmiro Bustos, "Tele y Transferencia son reconocidos desde la ansiedad, presente en las relaciones transferenciales y ausente cuando reina la tele; espontaneidad y ansiedad son dos aspectos que nunca ocupan el mismo lugar, cuando surge una desaparece la otra. Ambas tienen el mismo origen onto y filogenético. Marca el límite entre encuentros y desencuentros[...]. En terapia es sumamente útil comprender, desde el lugar del terapeuta, que la presencia de la ansiedad es un elemento importante de comprensión, que no debe ser auto referido, sino comprendido como la creación de señales para comprender los obstáculos comunicacionales, los que a su vez nos conducen a explorar sus raíces históricas" (1985, p.36).

La otra dificultad viene de la mano de la imagen del paciente, para sí mismo y para los demás. Esto supone una nueva lectura de la resistencia, este grado de "humillación" que el sujeto va a experimentar con la exposición de sus debilidades, sólo puede ser contrarrestado por la seguridad y la confianza que el grupo y el terapeuta le ofrezca. Por eso a mayor herida del narcisismo, mayor es la dificultad para la dramatización y por eso tenemos que plantear un tercer elemento a la hora de comprender las resistencias.

Ej. Daniel es un joven que acudió inicialmente a tratamiento por presentar dificultades de erección. Su relación con los otros miembros del grupo es excelente, es uno de los líderes afectivos del mismo y muy apreciado por las mujeres del grupo. Trascurre la dramatización donde observa que su dificultad está ligada a la exigencia, a tener que satisfacer al otro, y el convencimiento de que será incapaz de hacerlo. Se detiene la escena y se le señala su modo de pensar. Se le pregunta si este patrón relacional de satisfacer absolutamente el deseo del otro, asociado a la incapacidad de conseguirlo va más allá de sus relaciones sexuales. Apreciamos que se intensifica la angustia, que los fantasmas infantiles se han activado, y eso que los psicodramatistas llamamos personajes, o trocitos de sí mismo que están internalizados, hacen que la emoción surja y la escena se detenga. Era el momento de elaborar y distanciarse, continuar hubiera sido demasiado invasor para Daniel.

\section{La comprensión del cambio en psicoterapia psicodramática}

La contestación a la cuestión de la comprensión del cambio, la voy a presentar desde una idea que he mantenido a lo largo de mi vida: que la psicoterapia no se convierta en una técnica de acumulación de técnicas y que el terapeuta pueda seguir siendo un ser humano, con sus recursos y limitaciones, en su realización. 


\section{Una concepción relacional y holística}

En uno de mis primeros trabajos publicados sobre psicodrama (Herranz, 1991) pensaba en las relaciones causa-efecto, para poder entender la eficacia terapéutica. Ello me llevó a preguntarme dos cosas: qué elementos del psicodrama generaban o provocaban cambios, y qué lugar tenía en este proceso de cambio la relación terapéutica.

Con relación a la primera pregunta intenté separar los distintos elementos y repensarlos desde mi experiencia clínica:

El primer elemento que consideré fue el encuadre, como un invariante, como una constante. En mí latía el pensamiento de José Bleger "Cuando en lo conocido aparece lo desconocido eso es lo siniestro" (Bleger, 1988, p.45).

Consideré imprescindible un encuadre rígido como el único modo de poder encontrar procesos comunes y comparables.

Después me detuve en el espacio, el movimiento, el cuerpo, el diálogo que se establecía entre paciente y terapeuta, este diálogo era muy complejo, no pude llegar a concluir cómo se generaba una danza útil de cadencias de sonidos, movimientos y lugares, pero sabía que había un registro emocional que informaba cuándo el campo era tenso y cuándo era protector, cuándo la cercanía permitía la intervención y cuándo la "agresividad alejaba al terapeuta del paciente". Ese discurso que se construía era un proceso relacional, era una danza que concluía en la dramatización, o en el compartir sin dramatización.

Con mi pensamiento causal y con pretensiones experimentales llegué a analizar las intervenciones y su eficacia. Lo que tenía era una persona frente a otra, dentro de un marco compartido por el paciente y el terapeuta, un campo de interacciones, entonces tenía que crear interacciones que se aliaran con la salud. Elegí, sin un criterio teórico común, diferentes estrategias de intervención: La provocación, las paradojas, la autorrevelación por parte del terapeuta, el recurso a la imagen, la interpretación. Diseñé procedimientos para saltar las resistencias, como el juego del sueño, donde vi la utilidad de recurrir a lo simbólico para salir de una dificultad en el tratamiento:

\section{Juego del sueño}

Ante la queja de los pacientes de apatía, desgana, aburrimiento o cansancio del tratamiento diseñé una secuencia de acciones.

- Que se coloque en la postura que desee para dormir, que cierre los ojos y que imagine que está durmiendo.

- Le pido que desde lo imaginario, manteniendo los ojos cerrados imagine que se despierta del sueño, que recorra despacio su alrededor, que mire quién hay allí, qué lugar es ese, que se detenga y se mire a sí mismo.

- Que recoja las sensaciones: cómo está, las percepciones, cómo va vestido, qué edad tiene...

- Cuando el paciente ha localizado la escena, le pido que mire qué quiere hacer, qué quiere pedir, y que lo haga.

- Le pido que vuelva al primer espacio de la imaginario y manteniendo los ojos cerrados que mire cómo se encuentra.

- Le sugiero que, cuando lo desee, vaya abriendo los ojos y se incorpore, esta última fase es una fase de Integración tras el recorrido por el mundo de lo imaginario, en el proceso terapéutico.

Este procedimiento surgió como casi siempre, al menos para mí, por azar y necesidad. Tuve que introducir lo imaginario en lo imaginario para saltarme las resistencias. Leí que el paciente no podía continuar trabajando sus temores desde un registro tan presentacional como el que estaba siguiendo conmigo, no podía pedirle al terapeuta, y sólo usando la resistencia al servicio de la resistencia pudimos desatascar el miedo a pedir. La ver- 
güenza de la petición se cubría con el espacio de lo imaginario y la herida se reparaba desde un lugar que servía como intra-intermediario de los objetos internos y la relación terapéutica.

De este primer trabajo llegué a algunas conclusiones satisfactorias y otras me abrieron más preguntas. Había estrategias que provocaban cambios más o menos estables, pero la técnica que se elegía no era neutra y la relación paciente-terapeuta se empezaba a ver modificada. Esto me llevó a plantearme un concepto tan viejo como la responsabilidad en la eficacia del tratamiento: ¿Quién es el responsable de que funcione o no lo haga? Sólo hay tres posibilidades: el paciente, el terapeuta, o el procedimiento utilizado; hoy añadiría una cuarta, algo que incluye a todos, pero no está en ninguno de ellos, la multiplicación de fuerzas convergentes que de manera sincrónica generan un efecto reparador de las heridas emocionales.

En su momento busqué la contestación a la pregunta de la eficacia terapéutica en dos direcciones, una epistemológica y otra puramente empírica y clínica, apoyada en el tratamiento y seguimiento de casos (Herranz, 1993a, 1993b, 1994, 1995, 1996a, 1996b, 1997, 1998a, 1998b, 1998c, 1998d, 1999a, 1999b, 1999c, 1999d, 2001, 2004).

\section{Una respuesta Epistemológica}

Coincidiendo con esta búsqueda intenté sistematizar mis esfuerzos en algunos trabajos por encontrar un modo de buscar el responsable del éxito y el fracaso de los tratamientos. (Herranz 1992a, 1992b, 1992c, 1992d, 1992e, 1993a, 1993b). La búsqueda nunca fue tranquila, suponía un desasosiego personal, una lucha con lo establecido.

La epistemología sistémica me ofrecía otro modo de entender los sucesos, la angustia que para un psicólogo con formación racionalista y experimentalista suponía la lógica lineal se veía, al menos momentáneamente, anestesiada por otra forma de pensar.

La lógica lineal, característica de las ciencias físicas, y envidiadas siempre por los psicólogos, nos habían enseñado que un suceso que causa otro pasa a ser la causa, el responsable, el culpable de que aparezca el efecto.

Este modo de entender las cosas, a su vez, permitía mantener el mito de la neutralidad del observador. Por contraposición, el pensamiento sistémico descentra al individuo de su responsabilidad y sólo le otorga el título de corresponsable, el sujeto pasa a verse como parte de un sistema y nuestro yo individual pasa a ser entendido como una dinámica relacional. En este paradigma se sustituye la linealidad por la reciprocidad, la recursividad y la responsabilidad compartida. Desde este pensamiento se redefinían los conceptos de salud y enfermedad. La primera cibernética consideraba que todo síntoma se entendía si encontrábamos el significado en su contexto, y de ahí se llegó a creer que el síntoma era "Funcional" dentro de un contexto "disfuncional" para el propio sujeto.

Con este modo de pensar transcendí el marco de intervención familiar, y recordé y recogí la idea de conducta como un todo indivisible. Mis lecturas de Pichón Rivière y José Bleger, continuaban teniendo un peso importante.

No sería descabellado pensar que una persona es un sistema que forma parte de otros, pero que tiene a su vez que funcionar de una manera equilibrada (homeostática) en sus diferentes áreas de conducta. De tal manera, que el síntoma puede aparecer, en el ámbito del cuerpo, de la mente o el mundo externo, pero mi modo de pensar no dejaba de ser interrelacional y contextual. Fruto de este pensamiento, me acerqué a intentar explicar la modificación de diferentes síntomas desde lo neurótico (Herranz, 1992a) a lo psicosomático (1992b).

Pero empezó a surgirme la necesidad de precisar las limitaciones de mis afirmaciones y explicitar mis procesos de pensamiento. Quería validar lo que hacía desde la mayor claridad intelectual que me fuera posible. Tenía muy clara la diferencia entre los hechos y las explicaciones de los hechos:

Para J. Bleger, "La psicología debe estudiar el drama, y el drama es un hecho. El hecho psicológico es un segmento de la vida del individuo particular, es inseparable de dicho individuo, por eso justamente es un hecho psicológico" (1973, p.32). 
Y para mí la comprensión de ese hecho, sólo era posible desde las tres áreas fenoménicas comprometidas en el proceso de comportamiento (mente, cuerpo y mundo exterior).

Desde esta manera de leer la psicoterapia, llegué a otro lugar: La semántica del síntoma. El síntoma tiene un valor comunicacional, conocido o no, guiado o no por la intencionalidad, tiene un valor heurístico de los lugares, sistemas y contextos de los que forma parte.

Aquí no quiero inducir a error al lector, cuando hablo de la semántica del síntoma no quiero hacer pensar que los síntomas van dotados de significado intrínseco, los significados pueden ser múltiples e individuales, y su explicación es un esfuerzo de comprensión que no será única ni objetivable.

La continuación de este trabajo me llevó a unir dos principios: la teoría de Dalmiro Bustos sobre el rol complementario patológico con el principio de circularidad.

Busqué en la epistemología circular sistémica una definición de personalidad (Bateson, 1979; Dell, 1985; Maturana, 1985):

Bateson (1972, p.61) carácter es:

- "Una red de premisas ontológicas (en cuanto son generadas y dan cuenta de la naturaleza que la constituye) y epistemológicas (en cuanto metaconocimiento) que especifican cómo las personas deben comprender como relacionarse con el mundo".

Mi diferenciación anterior entre hechos y significados, me llevó a buscar una primera regla que explicara las intervenciones que conducían al error. Desde el psicodrama bipersonal pude representarme dos campos de interrelación, los juegos relacionales explícitos y los implícitos. La psicoterapia bipersonal, para mí, era como la definía Pichón Riviere, bicorporal y multipersonal. Cada uno de nosotros, paciente y terapeuta tenía una serie de relaciones internas, o mejor, éramos una serie de relaciones internas.

No dejaba de tener en cuenta el principio de D. Bustos: "un rol que queda fijado a su complementario, pasa a configurar un rol complementario interno patológico" (1985, p.33). Su comprensión de este principio me llevaba a estar convencido de que la respuesta que un sujeto dio en algún momento de su ciclo vital en una situación emocionalmente traumática por comisión o por omisión le permitió adaptarse a la situación, adaptarse como requisito supervivencial. Más allá de su propia voluntad está la voluntad de la vida por perpetuarse.

Este patrón original de respuesta se va a generalizar a las relaciones con todos los sujetos que, en mayor o menor grado, se acomoden a esa primera escena fundante de la identidad.

Por tanto, la psicopatología de la intervención pasé a entenderla como una repetición, el paciente repetiría su conducta con el terapeuta, y el terapeuta tendría que ser capaz de desenmarañar la red que iba a atrapar su capacidad de generar respuestas alternativas.

¿Cómo hacerlo? Se podría encontrar un procedimiento, que fuera en realidad un metaprocedimiento, una lógica que guiara el proceso terapéutico (Herranz 1992d). Los principios básicos, de lo que entonces denominé lógica de la intervención, fueron los siguientes: En primer lugar diferencié los componentes afectivos que surgen en la relación terapéutica de los cognitivos y conductuales. Recuerdo siempre mi obstinación por decir que los sentimientos cambian los sentimientos y el pensamiento cambia el pensamiento.

En el ámbito cognitivo y conductual sostenía que el papel del Terapeuta debía complementar el rol no actuado por el paciente. Es decir, el complementario al patológico del paciente. El paciente desempeña un rol patológico fijado a un rol interno complementario, y por tanto no actúa su rol funcional. Ej si se muestra incapaz, no muestra su capacidad.

Si tuviera que plantear una fórmula como si de un procedimiento lógico se tratara, la fórmula del cambio sería:

Siendo A = Cambio, $\mathrm{a}^{\prime}=$ el rol no actuado por el paciente y $\mathrm{a}^{\prime \prime}=$ el rol complementario al no actuado por el paciente (por parte del terapeuta), el cambio sería:

$A=a^{\prime} y a^{\prime \prime}$ 
Si un paciente se muestra incapaz, sin ideas, mi rol como terapeuta deberá consistir en tratarle como si fuera capaz y tuviera la potencialidad de generar sus propias ideas.

Ahora bien, esta regla de intervención debe ir unida a un segundo principio de complementariedad que denominé complementariedad afectiva. Pero explicar este segundo principio requiere mostrar algunos supuestos en los que me apoyaba:

1. Entiendo que un sujeto enferma de inseguridad afectiva. Enfermamos de inseguridad por amor y de odio (Pichon Rivière, 1985).

2. Los temores básicos son dos: persecutorio: temor al ataque. Depresivo temor a la pérdida (Kesselman, 1973).

Ambos temores se podían entender como dos apariencias de un solo temor, el miedo a la muerte, la vida teme morir y se muere por omisión o comisión.

3. Estos temores impregnan de forma diferente a un sujeto en función de su momento evolutivo, es necesario no olvidarlo cuando nos planteamos el impacto de la relación con el otro.

Las conclusiones a las que conduce este segundo principio de complementariedad afectiva son que en cada uno de los temas conflictivos que vaya trabajando el paciente tiene que sentir la seguridad en el otro, la seguridad de no ser abandonado ni agredido. Y esa seguridad, seguirá una línea cronológica, en función del momento en que se originó el daño, en función del momento evolutivo donde se cristalizó, se detuvo el aprendizaje del rol. Es decir, la seguridad de un adulto en un adulto no es complementaria de la relación de un niño de doce, siete... años con su madre, padre... por eso sólo se dará de posibilidad de cambio si previamente se ha generado "la relación afectiva complementaria", que estaba convencido de que consistía en la seguridad de no ser agredido, ni abandonado como se sintió en el vínculo en el que quedó fijado su rol patológico.

Este constructo se sintetizaba en el siguiente esquema: (Ver Anexo 1).

\section{ANEXO 1}

Proceso terapéutico $=$ Metanivel de Intervención .

Microproceso $=$ Niveles de intervención

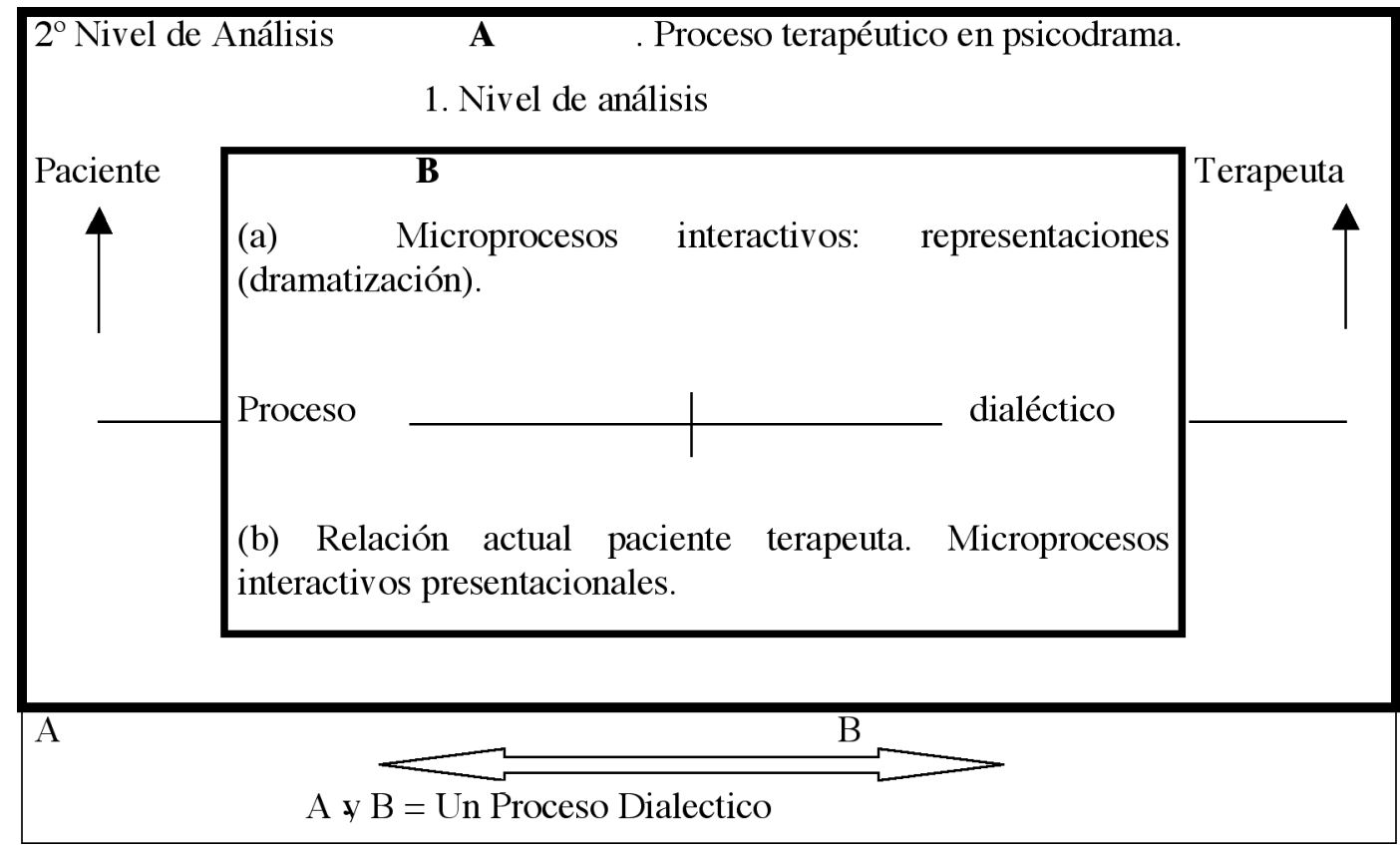


Desde El Pensamiento Actual: Una Posición Débil, o Una Posición Compleja: La Posición Del Inventor. La Posición Del Investigador

\section{La posición del inventor: Dos modos de pensar el cambio}

Si partimos de aceptar que no existe un único modo de resolver un problema, y que no se ha comprobado que haya una diferencia manifiesta entre la eficacia de unos procedimientos de intervención sobre otros, parecería lícito, permitirnos inventar soluciones nuevas para viejos problemas, o colocarnos en el papel de inventor de soluciones nuevas junto a nuestros pacientes. Aquí estaríamos obviando una teoría específica, o si se quiere, estaríamos en una posición metateórica que nos señalaría que el peso explicativo de las distintas teorías dista mucho de traducirse en eficacia clínica, por lo que podríamos colocarnos en una posición pragmática que se traduciría en crear las "herramientas que valgan" para producir cambios en los pacientes.

A modo de un intento de implementación de este modo de pensar en el quehacer de la sesión psicodramática, vamos a mostrar dos opciones terapéuticas:

a) Se le pide al paciente que cree respuestas diferentes, trabajaría siempre hacia el futuro, se examinarían las situaciones que el sujeto considera irresueltas o irresolubles, y se buscan respuestas más adaptativas, más beneficiosas para él, más deseadas.

b) Crear, inventar respuestas, con la tolerancia del paciente, consciente o no de lo que se está realizando.

a. Una vez que el paciente elige la respuesta que desea dar, se le dice que la ponga en práctica. ¿Y ya está? No, que el sujeto se sienta capaz de ponerla en práctica no significa que se haya generado un cambio interno. Para ello nos detenemos en las limitaciones que él se atribuye y pasamos a enfrentarnos al peso "de presente" que quiere dar a esas situaciones, y a transformarlas.

Ej. Un paciente que presenta síntomas obsesivos (miedo a contaminarse con el aire de la ciudad, miedo que se inicia después de un sueño). Se le pide que nos diga qué le gustaría hacer, cómo desearía sentirse. Su respuesta es evidente: sin miedo a asfixiarme si respiro. A continuación se le pide que ensaye esa conducta en la sesión, lo hace y se siente bien. Ese sentirse bien va acompañado del escepticismo: pero fuera voy a seguir teniendo miedo. Entonces el problema se focalizará en el poder que él quiere darle a su miedo cuando salga a la calle. Sin detenerme excesivamente en los pasos intermedios, el objetivo será ir a buscar en qué medida el sujeto decide dejarse asustar (castigarse) o darse la posibilidad de vivir sin miedo, sin culpa. En este momento podemos recurrir a todo tipo de ejercicios dramáticos, juegos, "apoyos técnicamente admitidos del terapeuta" para que el paciente se permita hacer lo que desea hacer.

Este modo de trabajar lo consideraríamos una colaboración guiada por el terapeuta, dado que el resultado es el fruto de un esfuerzo compartido, y donde la solución es la aceptación por el paciente de un cambio, dentro del margen de cambio que él considera permisible.

b. Habría otro modo de trabajar donde el paciente tiene un lugar menos activo en la búsqueda de las soluciones. En este modo de proceder el terapeuta abre una vía de trabajo donde el paciente desconoce el fin y es un receptor del mismo.

Ej: Un paciente que presenta un trastorno de personalidad por dependencia, con síntomas obsesivos, y en fase de recuperación del alcoholismo. Dedica las sesiones a recriminarse e inculparse por lo mal que se ha portado con su mujer, y el temor que tiene a sus opiniones. Esta idea la ha convertido en una rumiación. Cuando se le intenta señalar su modo de autoinculparse se observa su tenacidad para el maltrato.

El terapeuta le propone que piense en las cosas que él desee, que empiece a fantasear acerca de lo que le gusta, utilizándose una técnica de control cognitivo añadido. Se le dice que cuando las ideas molestas interrumpan las fantasías deseadas, repita una vez en voz alta la idea que le perturbe y que posteriormente se dedique de nuevo a fantasear con sus proyectos y sus ilusiones. 
Y funcionó, sí, para quitarle el peso de lo obsesivo y poder empezar a conectar con lo que él quería. Creemos que la razón está en lo dicho por el terapeuta, en la fuerza de la dependencia que él traslada al tratamiento, y a un poder mágico que se le da a la repetición en voz alta, característica del pensamiento mágico que utiliza para obsesionarse. Este tipo de intervenciones suponen búsquedas de nuevas respuestas, sobre todo dirigida a que los síntomas dejen de impedir el proceso terapéutico.

\section{La posición del investigador: Un pensamiento causal evolutivo}

Cuando hago psicodrama desde un pensamiento causal-evolutivo, me convierto en un descubridor. Entiendo que tengo que rastrear, a partir de problemas actuales, conflictos subyacentes, tácitos e inconscientes del sujeto (en alguna medida).

Esto supone la conceptualización del psicodrama como un "proceso terapéutico" donde el presente en la conducta y la patología del sujeto remite a un pasado que yo reconozco desde un modelo teórico. El reconocimiento desde un modelo teórico, a su vez, puede suponer dos actitudes: una que sería de pura comprobación de lo ya conocido, y otra que sería de guía con la suficiente flexibilidad para otorgar a la información del paciente y poder replantear lo conocido desde el modelo teórico.

Este planteamiento conlleva que yo, no sólo conozco la técnica sino que, tengo una teoría del sufrimiento que voy a abordar con la técnica y asumo unos principios que garantizan que lo que hago toma la dirección adecuada para llegar a mis objetivos. Esto significa que yo tengo una teoría de por qué es eficaz la técnica y de qué ha causado la dolencia que estoy atendiendo.

En psicodrama, creemos que el sufrimiento hay que buscarlo en el entramado emocional del sujeto. A partir de ahí desarrollamos los medios para que el sentimiento se libere de las apariencias engañosas que el sujeto utiliza para soportarlo y mantenerlo. Si tuviéramos que elegir dos axiomas que rigen este modo de intervenir serían:

1. El reconocimiento de las emociones es imprescindible para que se produzca un cambio en el sujeto. El cambio no vendrá dado por la intervención sobre un código abstracto, "una reflexión sobre los sentimientos", sino por la repetición de las situaciones que permitan al sujeto la reactivación emocional de las vivencias importantes de su vida.

2. Las situaciones que han sido traumáticas para el sujeto no se borran con el tiempo, sino que mantienen una huella que no es pasado sino presente y guía la conducta actual del sujeto. Esas situaciones traumáticas son relacionales, han intervenido personas existencialmente imprescindibles para el sujeto que le han obligado a adaptarse a una situación desadaptativa desde el punto de vista de su propio desarrollo.

Cuando nos acercamos desde una concepción causal-determinista al sufrimiento, vamos a ser rastreadores "descubridores" del sentimiento a lo largo del tiempo y de las situaciones transmitidas por el sujeto. Así llegaremos a las que consideraremos nucleares, originales que se enlazan unas con otras a modo de un racimo (Bustos, 1995), de una cadena asociativa. Aqui la acción, la puesta en acción de las situaciones va a tener una función esencial en el reconocimiento de las emociones e influirá el papel desempeñado por los distintos personajes de la vida del paciente.

Hasta aquí parecería que estamos tomando una posición "ingenua" en la intervención, que se podría definir como la actitud del "no saber", también denominada "heurística negativa" (Villegas 1993, 1995), que supondría una comprensión paso a paso de las situaciones dadas por el sujeto, y donde el papel del terapeuta sería ir acompañando al paciente en las distintas situaciones para que se fuera dando una liberación emocional y la elaboración cognitiva de la situación: "catarsis de integración". De un modo sintético el método se reduciría a:

1. Búsqueda de las escenas dolorosas para el paciente (que hipotetizamos determinan sus conductas desadaptativas actuales).

2. Dramatización de las mismas en el aquí y ahora de la sesión de psicodrama. 
3. Esperar a que el paciente vaya uniendo esas escenas con las que le precedieron evolutivamente y que se organizan en torno al mismo sentimiento.

4. Sustituir la respuesta original (adaptada a una situación desadaptada) por una respuesta adaptativa en su momento de vida presente.

Las destrezas del terapeuta serían esencialmente las de ser un buen acompañante en el recorrido que hace el paciente por su propia historia y darle el apoyo suficiente para que genere nuevas respuestas, para que pierda el miedo a hacerlo.

Pero hay otro planteamiento más determinista, que se puede enlazar con el psicodrama y que procede del psicoanálisis. Parte de una duda razonable, cómo el conocimiento que el paciente transmite sobre su historia es algo más que una versión distorsionada, cuando no errática, imprecisa, o caótica, frente a la cual existe una teoría de la psicopatología evolutiva, que es el resultado del uso de una herramienta heurística (el psicoanálisis) a una infinidad de casos que presentan la misma naturaleza de sufrimiento, y que organizando la información del sujeto desde este modo de comprenderla, dota a los pacientes de más medios para encontrar la respuesta a las situaciones que le conflictúan.

Esta segunda posibilidad de trabajar en psicodrama, puede ser menos actual. Si se quiere, está más alejada del pensamiento postmoderno, pero permite desatascar situaciones cerradas en el abordaje del paciente. Aquí el descubridor ya no es ingenuo, es un descubridor que confía en su modelo teórico. El modo de trabajar se modificaría esencialmente en que el terapeuta no aceptaría los significados del paciente, sino que le guiaría por aquellos que él considera explican mejor la información que trae el paciente. Si se quiere, aquí el terapeuta hace que el paciente recorra territorios que para él son relativamente desconocidos, y que él no vería como una foto de su historia si no se le hiciera ver.

\section{Conclusiones}

De Moreno se decía que tenía un modo de pensar muy operativo, su espontaneidad, su ingenio y su brillantez intelectual hacía simple la búsqueda de lo complejo.

Creo que si yo le preguntara cómo puedo saber qué produce el cambio en psicodrama, él me contestaría: pregúntalo. ¿A quién? , a lo que añadiría: pues a quién va a ser, a las personas que atiendes con psicodrama.

De esa pregunta a dos grupos de personas, que llevaban 24 horas de práctica psicodramática, he elegido dos frases que resumen y representan la opinión generalizada de lo que les ayuda a cambiar:

"El grupo sostiene y encuadra, potencia lo bueno y desdibuja el malestar a través del compromiso y la escucha participativa. Poco a poco vamos reconociéndonos más y eso nos ayuda a cambiar".

"La posibilidad de poner fuera lo sentido y visualizarlo, resignificar lo doloroso".

Quizás lo que produce cambios a través del psicodrama es reconocernos como seres humanos en un proceso permanente de transformación aprendiendo a hacerlo y aceptando las renuncias, el sufrimiento y la satisfacción de hacerlo.

\section{Referencias}

Bateson, G. (1972). Pasos hacia una ecología de la mente. Buenos Aires: Carlos Lohlé.

Bateson, G. (1979). Mind and nature. A necessary unity. New York: Dutton.

Blatner, H. (1973). Psicodrama. Cómo utilizarlo y dirigirlo. México: Pax México.

Blatner, A. (2002a). Historical distortions regarding psychodrama in the professional literature. En www. blatner.com

Blatner, A. (2002b). Theoretical foundations of psychodrama. En www.blatner.com 
Bleger, J. (1973). Psicología de la Conducta. Buenos Aires: Paidós.

Bleger, J. (1988). Psicoanálisis y dialéctica materialista. Buenos Aires: Nueva Visión.

Bustos, D. M. (1985). Nuevos rumbos en psicoterapia psicodramática. Individual, parejas y grupo en función social. La Plata, Buenos Aires: Momento.

Bustos, D. M. (1995). Novas Cenas para o Psicodrama. O teste da mirada e outros temas. Sao Paulo: Agora.

Dell, P. F. (1985). Understanding Bateson and Maturana: Toward a Biological Foundation for the social sciences. Journal of Marital and Family Therapy, 11, 1-20.

Herranz, T. (1990). Psicodrama individual y bipersonal: aspectos teóricos y metodológicos. Vínculos, 1, 47-102.

Herranz, T. (1991). Psicodrama bipersonal: Aspectos clínicos 1. Etiopatogenia vincular del fenómeno masoquista en la mujer ( $1^{\text {a }}$ Parte). Vínculos, 2, 37-68.

Herranz, T. (1992a) Precisiones terminológicas desde una concepción epistemológica Gestáltica. Larda. Año $11,32,5-11$.

Herranz, T. (1992b). La respuesta psicosomática en el proceso de intervención familiar. Vínculos, 5, 47- 57.

Herranz, T. (1992c). Tu circularidad y la nuestra. Informaciones psiquiátricas, 126, 399-405.

Herranz, T. (1992d). Procesos, estructuras y emociones en psicodrama. Vinculos, 6, 19-32.

Herranz, T. (1992e). Error y lógica de la emoción en terapia familiar. XIII Jornadas nacionales de terapia familiar, 78-90. Cáceres: FEATF.

Herranz, T. (1993a). Dinámica familiar, una perspectiva diferente. $3^{\text {a }}$ Jornada en Atención primaria. Área VIII, Libro de Comunicaciones, 11-17.

Herranz, T. (1993b). Psicodrama bipersonal y personalidades masoquistas: El significado de las crisis de angustia y la sexualidad perversa. Informaciones psiquiátricas, 132 (2 $2^{\circ}$ trimestre) 243-252.

Herranz, T. (1994). Microprocesos interactivos y experiencia emocional correctiva. XV Jornadas nacionales de Terapia familiar, 397-408. Vitoria: FEATAF.

Herranz, T. (1995). Cartas a/de Daniel. Informaciones psiquiátricas, 140 (2º trimestre), 253-257.

Herranz, T. (1996a). La reparación del abandono: psicodrama con niños institucionalizados. XII reunión de la A.E.P, 147-162. La Coruña.

Herranz, T. (1996b). Trastornos Narcisista y Borderline ¿Una frontera permeable? Revista Brasileira de Psicodrama, 4, 21-34.

Herranz, T. (1997). La violencia de los niños. III Congress of Family Therapy. Barcelona, 1-5 Oct.

Herranz, T. (1998a). ¿Psicoterapia individual y/o sistémica? Mosaico, 13 (3 trimestre), 16-18.

Herranz, T (1998b) Un estudio bibliométrico: de dónde venimos en psicodrama. Psicodrama, una propuesta de futuro (pp. 73-93). Sevilla: Padilla

Herranz, T. (1998c). Violencia y poder conversemos. Psicodrama una propuesta de futuro (pp. 93-110). Sevilla: Padilla.

Herranz, T. (1998d). Construcciones y actuaciones: un proceso reconstruccionista aplicado al trastorno narcisista de personalidad. Psicodrama, una propuesta de futuro (pp. 215-246). Sevilla: Padilla.

Herranz, T. (1999a). ¿Qué psicodrama sobrevivirá?. XV Reunión de la A.E.P, Barcelona, 21-24 de Octubre, $139-158$.

Herranz, T. (1999b). Vidas condicionadas. XV Reunión de la A.E.P, Barcelona 21-24 de Octubre, 159 -166.

Herranz, T. (1999c). Psicoterapia Psicodramática individual. Bilbao: Desclée de Brouwer.

Herranz, T. (1999d). Violencia infantil y psicodrama. Annaes, II Congreso Iberoamericano de Psicodrama, 71-91.

Herranz, T. (2001). Psicodrama y salud. Madrid: UPCO.

Herranz, T. (2004). Psicodrama clínico: teoría y técnica. Madrid: Ciencias Sociales.

Kesselman, H. (1973). Psicoterapia Breve. Buenos Aires: Fundamentos.

Maturana, H (1985). Biología del Fenómeno Social. Terapia Familiar, 53-70.

Monteiro, M. (2000). Deconstruçao e Reconstruçao da teoría psicopatologica no psicodrama clínico, uma proposta metodológica. Leituras, 33, 1-8. 
Moreno, J. L. (1961). Fundamentos de la sociometría. Buenos Aires: Paidós.

Pichón Rivière, E. (1985). Teoría del vínculo. Buenos Aires: Paidós.

Perazzo, S.(1994). Ainda e sempre psicodrama. Sâo Paulo: Agora.

Perazzo, S. (2004). ¿Qué teoría de qué psicodrama?, en Herranz, T. (2004), Psicodrama Clínico: Teoría y Técnica. Madrid: Ciencas Sociales.

Villamarzo, P. F. (1991). Cursos sistemáticos de formación psicoanalítica III. Temas Clínicos: Neurosis. Madrid: Marova.

Villegas, M. (1993). La entrevista evolutiva. Revista de Psicoterapia, 14/15, 38-87.

Villegas, M. (1995). La construcción narrativa de la experiencia en psicoterapia. Revista de Psicoterapia, 22/23 (2/3er trimestre) 5-21.

Manuscrito recibido: 27/01/2010

Revisión recibida: 22/02/2010

Manuscrito aceptado: 22/02/2010 